\title{
Experimental Study on Anisotropic Strength and Deformation Behavior of a Coal Measure Shale under Room Dried and Water Saturated Conditions
}

\author{
Jingyi Cheng, ${ }^{1,2}$ Zhijun Wan, ${ }^{1}$ Yidong Zhang, ${ }^{3}$ Wenfeng Li, ${ }^{1,2}$ \\ Syd S. Peng, ${ }^{2}$ and Peng Zhang ${ }^{2}$ \\ ${ }^{1}$ School of Mines, Key Laboratory of Deep Coal Resource Mining, Ministry of Education of China, \\ China University of Mining and Technology, Xuzhou, Jiangsu 221116, China \\ ${ }^{2}$ Department of Mining Engineering, West Virginia University, Morgantown, WV 26505, USA \\ ${ }^{3}$ State Key Laboratory of Coal Resources and Safe Mining, China University of Mining and Technology, Xuzhou, Jiangsu 221116, China
}

Correspondence should be addressed to Zhijun Wan; zhjwcumt@hotmail.com

Received 2 October 2014; Revised 26 January 2015; Accepted 29 January 2015

Academic Editor: Marcin A. Lutynski

Copyright (c) 2015 Jingyi Cheng et al. This is an open access article distributed under the Creative Commons Attribution License, which permits unrestricted use, distribution, and reproduction in any medium, provided the original work is properly cited.

This paper presents an experimental investigation of anisotropic strength and deformation behavior of coal measure shale. The effect of two factors (i.e., anisotropy and water content) on shale strength and deformation behavior was studied. A series of uniaxial and triaxial compression tests were conducted on both room dried and water saturated samples for different lamination angles. The test results indicate that (1) the compressive strength, cohesion, internal friction angle, tangent Young's modulus, and axial strain corresponding to the peak and residual strengths of room dried specimens exhibit anisotropic behavior that strongly depends on the orientation angle $(\beta) ;(2)$ in comparison to the room dried samples, the compressive strength and Young's modulus as well as the anisotropy are all reduced for water saturated specimens; and (3) the failure mechanism of the samples can be summarized into two categories: sliding along lamination and shearing of rock material, with the type occurring in a particular situation depending strongly on the lamination orientation angles with respect to the major principal stress. According to the findings, it is strongly recommended that the effect of anisotropy and water content on the strength and deformation behavior of the rock must be considered in ground control designs.

\section{Introduction}

Shale is one of the most abundant rock materials in coal mines and forms the bulk of the roofs and floors of underground coal mines. Consequently, most cases of ground control failure are associated with shale. Among the 36 cases with detailed descriptions of geological conditions depicted by Peng [1], there were 32 cases with the immediate roof being shale, and all 9 roof fall cases occurred in shale strata.

Being the weakest part of shale, laminations play a key role in many kinds of ground control failures but its role in controlling rock mass behavior has been mostly ignored by researchers and engineers of the coal mining industry [2]. Current research on ground control design and analysis of the causes of ground control failures using computer modeling and physical simulation are largely based on the assumption that the mechanical response of shale is isotropic [3]. However, because of the presence of laminations, the behavior of sedimentary rock is anisotropic. During mining, the stresses in the roof strata redistribute continuously. The orientation of the major principal stress $\left(\sigma_{1}\right)$ with respect to the laminations or foliation of sedimentary rock may not be in the vertical or horizontal directions, and the failure strength of the rock mass is highly dependent on the anisotropic properties of the sedimentary rock. Hence, anisotropy must be taken into consideration in the dynamic analysis of geologic structure or in the prediction of dynamic disasters in engineering projects [4].

In the past few decades, the strength anisotropy of many kinds of rock has been investigated, such as shale and slates 
in [4-8], gneisses and schists in [9-11], phyllites in [12], sandstone in $[7,13]$, and artificial transversely isotropic rock in [14-16]. Their works demonstrate that the failure strength of anisotropic material is related to the inclination angle $(\beta)$ of the specimen laminations with respect to the direction of the major principal stress. Ramamurthy [12] stated that the maximum failure compressive strength is at $\beta=0^{\circ}$ or $\beta=90^{\circ}$ and the minimum value is around $\beta=30^{\circ}$. Meanwhile, several investigators $[8,12,16-19]$ have proposed a series of failure criteria to predict the strength of anisotropic rocks. By observing the failure processes and modes, several failure mechanisms have been proposed by researchers on different kinds of rock $[5,8,14]$. In spite of those attempts to investigate the mechanical properties of shale, the anisotropic strength and deformation behavior, especially the failure mechanism and the postfailure behavior of coal measure shale, remain obscure.

In addition to the presence of laminations, another important factor controlling shale behavior in coal mines is water content, including liquid water (manmade or natural, e.g., water inrush from the roof and flooding) and high moisture content ventilation air. It must be pointed out that because of the abundance of roof water, this issue is more serious in Chinese coal mines [20-22] than those in most other countries. In the past, some researchers [6, 23-26] have investigated the impact of ventilation air moisture on shale. Their work demonstrated that the properties of shale changed greatly as the water content increased. However, those studies dealt with the special situation when the rock surface was exposed to moisture carried by ventilation air, instead of the more general case where underground shale tends to be immersed in water most of the time. Furthermore, the detrimental effects of high water content on the mechanical properties of different types of rock have been investigated in [27-33]. But most of these tests were conducted under unconfined conditions, and few tests were performed on shale, especially coal measure shale, and none of them considered the effect of water content on rock anisotropy. Hence, it is of great value to conduct triaxial tests on the water saturated samples to evaluate the effect of water.

In this research, the uniaxial and triaxial compression tests were conducted with the confinement in the range of engineering interests to study the transverse anisotropy behavior of coal measure shale over the entire range of $\beta$ under either the room dried or the saturated conditions.

\section{Coal Measure Shale}

A well laminated shale block was obtained from the roof strata of Pittsburgh Seam of a surface mine in Frostburg, Maryland, USA. To minimize variations in the natural moisture content of shale samples and in order to obtain conditions similar to in-situ, the samples were kept wrapped in plastic sheets until specimen preparation. The procedure used for preparation followed the ASTM Standard D7012-10 [34]. Cylindrical specimens $50 \mathrm{~mm}$ in diameter with lengthto-diameter ratio of 2 were cored at different angles $\left(\beta=0^{\circ}\right.$, $15^{\circ}, 30^{\circ}, 45^{\circ}, 60^{\circ}, 75^{\circ}$, and $90^{\circ}$ ) to the lamination.

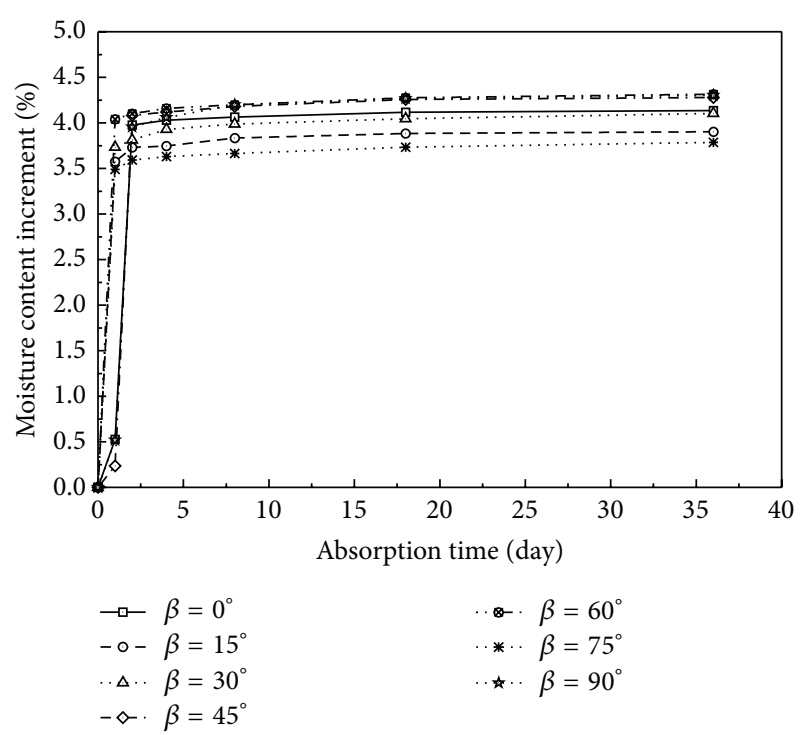

FIGURE 1: The moisture content increment of the specimens in the water saturated group.

Two groups of tests, room dried and water saturated, were performed at different values of $\beta\left(0^{\circ}, 15^{\circ}, 30^{\circ}, 45^{\circ}\right.$, $60^{\circ}, 75^{\circ}$, and $\left.90^{\circ}\right)$. With respect to the confining pressure applied to the samples during testing, Brady and Brown [35] collected data for about 900 in situ stresses measured by various investigators in various parts of the world and found that the maximum horizontal stress was $30 \mathrm{MPa}$ for depths up to $1000 \mathrm{~m}$. Since most coal mines in the USA and China range from 101 to $1000 \mathrm{~m}$ in depth, a maximum confining pressure of $30 \mathrm{MPa}$ should cover the stress conditions encountered. Hence, the confining pressure applied to the specimens for this research was no more than $30 \mathrm{MPa}$, that is, $0 \mathrm{MPa}$, $10 \mathrm{MPa}, 20 \mathrm{MPa}$, and $30 \mathrm{MPa}$ for room dried specimens.

Although the shale blocks were wrapped with plastic sheets during transport from the site to the laboratory, the specimens were unavoidably watered during the coring, cutting, and grinding processes. Hence, before the tests started, all the specimens in the room dried group were placed in the laboratory at room temperature for at least 2 weeks to release most of the moisture absorbed during specimen preparation. The moisture content for the specimens in the room dried group was obtained by performing standard tests. Small pieces of sample were dried at a temperature of $110^{\circ} \mathrm{C} \pm$ $5^{\circ}$ for at least $16 \mathrm{~h}$. By dividing the mass of lost moisture by the mass of solid particles, the moisture content was obtained. The test results show that the moisture content for the readyto-test specimens in the room dried group was $0.79 \%$.

All the specimens in the water saturated group underwent the same procedure as those in the air-dry group before they were immersed in water for about 36 days. For the specimens in this group, the moisture content increased to $3.79-4.23 \%$ due to immersion in water (Figure 1). Note that the terms "saturated" or "saturation" in this paper simply refer to the state achieved by immersing the specimens as described in this paper; it is difficult to achieve a full water saturation in this way. 


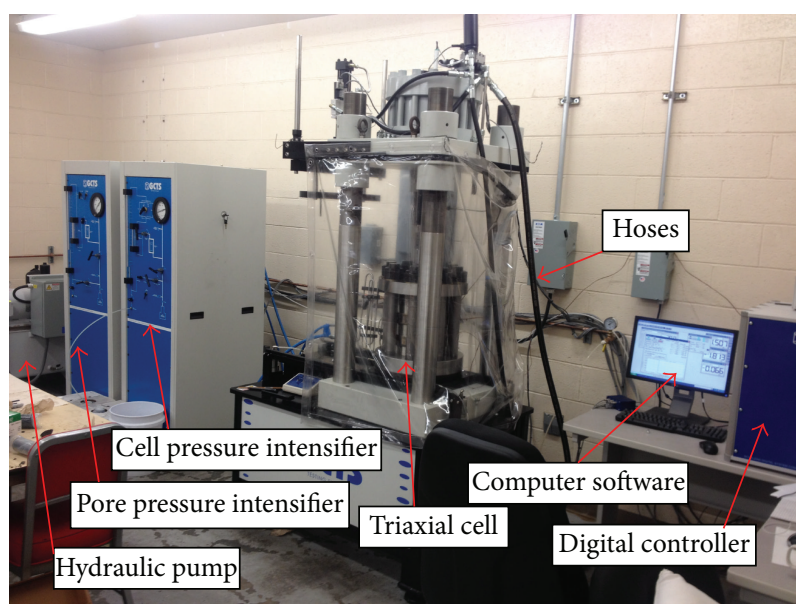

Figure 2: The GCTS triaxial rock test system.

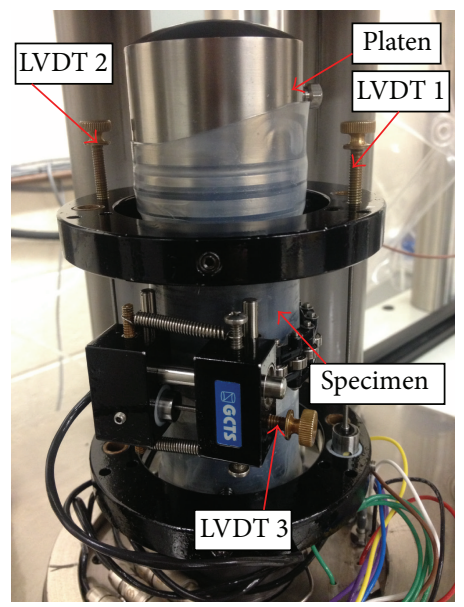

FIGURE 3: The layout of all 3 linear variable differential transformers (LVDTs).

\section{Apparatus and Testing Procedures}

The tests were carried out with the GCTS triaxial rock test system (RTX-1500) (Figure 2) housed in the Department of Mining Engineering of West Virginia University, Morgantown, WV, The United States. The testing system is equipped with two loading subsystems, a servo-controlled vertical loading subsystem with capacity of $1500 \mathrm{kN}$, and a servocontrolled confining pressure subsystem with capacity of $200 \mathrm{MPa}$. The stiffness of the testing frame is $1750 \mathrm{kN} / \mathrm{mm}$.

The axial and lateral strains were determined from data obtained by the linear variable differential transformers (LVDTs) shown in Figure 3. The LVDT 1 and LVDT 2 were used to measure the axial displacements and LVDT 3 was a circumferential lateral deformation measurement device using a chain to measure the lateral/circumferential strain of the specimens. All 3 LVDTs were calibrated before testing.

Before testing, the sample was placed between the base cap and the top end cap inside the triaxial cell and jacketed with the polyolefin heat shrink tube to seal the sample from the confining fluid. Then, LVDTs and various sensors were installed and the triaxial cell was placed onto the testing platform. A small differential stress $\left(\sigma_{1}-\sigma_{3}\right)$ of $0.5 \mathrm{MPa}$ was applied to ensure that the sample was in good contact with the upper platen. In other words, in the initial part of loading sequence, the axial stress is consistently $0.5 \mathrm{MPa}$ larger than the gradually increased confining pressure until reaching the planned level of confining pressure. During this period, the axial load was applied from a hydraulic pump with a constant strain rate of $0.002 \% / \mathrm{s}$ until the test was finished.

\section{Test Results}

Figure 4 presents the variations of axial strain $\left(\varepsilon_{a}\right)$ and lateral strain $\left(\varepsilon_{r}\right)$ versus the differential stress $\left(\sigma_{1}-\sigma_{3}\right)$ of room dried specimens (RD) under confining pressures of $0 \mathrm{MPa}, 10 \mathrm{MPa}$, $20 \mathrm{MPa}$, and $30 \mathrm{MPa}$ for different orientation angles $(\beta)$. The complete stress-strain curves corresponding to the water saturated specimens (WS) are also shown in Figure 4 marked with pink dots. For different orientation angles, the stressstrain curves, including both the prefailure and postfailure stages, exhibit different characteristics. The jagged portion of the stress-strain curves will be discussed in Section 5.4. Figure 4 shows that the water saturated samples have a lower compressive strength and Young's modulus as compared to the room dried ones.

\section{Discussion}

\subsection{Effect of Anisotropy and Confining Pressure on Compressive Strength of Room Dried Samples}

5.1.1. Peak Compressive Strength. Figure 5 shows the variation of the differential stress at failure $\left(\sigma_{1}-\sigma_{3}\right)$ and the corresponding sample orientation $(\beta)$ at different confining pressures $\left(\sigma_{3}\right)$ for room dried specimens. The compressive strength of shale is anisotropic and depends on its orientation angle $(\beta)$. It reaches the maximum at $\beta=0^{\circ}$ for confining pressures $10 \mathrm{MPa}$ and $20 \mathrm{MPa}$ and at $\beta=90^{\circ}$ for confining pressure $0 \mathrm{MPa}$ and $30 \mathrm{MPa}$. The minimum strength always occurs for samples with $\beta$ between $30^{\circ}$ and $45^{\circ}$ under all confining pressures except uniaxial compressive tests. Similar results have been obtained by several researchers $[5,8]$ for other kinds of rock.

Nasseri et al. [10] defined the intensity of anisotropy for the strength of transversely isotropic materials with the following two parameters:

$$
\begin{aligned}
& k_{1}=\frac{\left(\sigma_{1}-\sigma_{3}\right) \max }{\left(\sigma_{1}-\sigma_{3}\right) \min } \\
& k_{2}=\frac{\left(\sigma_{1}-\sigma_{3}\right) 11}{\left(\sigma_{1}-\sigma_{3}\right) \perp},
\end{aligned}
$$

where $k_{1}$ defines the ratio of the maximum to the minimum strength and $k_{2}$ is the ratio of the failure stress for the samples parallel to the laminations to those perpendicular to the laminations.

$k_{1}$ is $3.5,2.93,2.45$, and 2.14 for confining pressures 0 , 10,20 , and $30 \mathrm{MPa}$, respectively (Figure 6). In other words, 


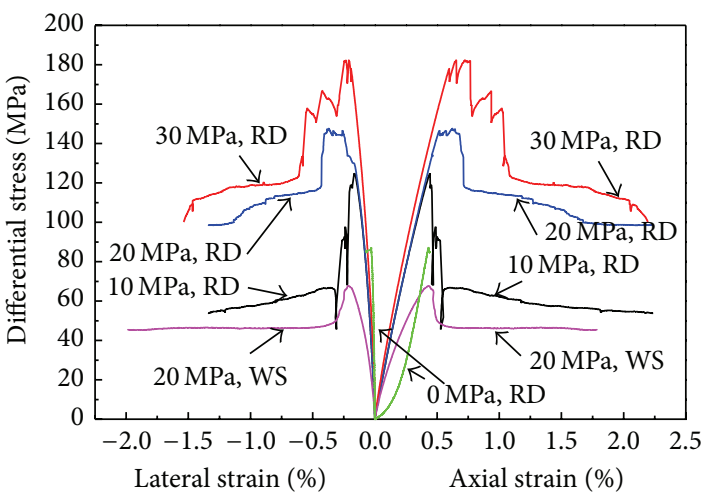

(a) $\beta=0^{\circ}$

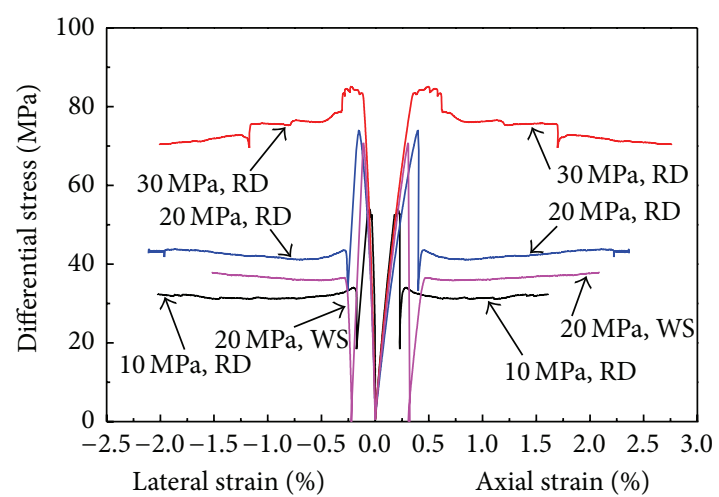

(c) $\beta=30^{\circ}$

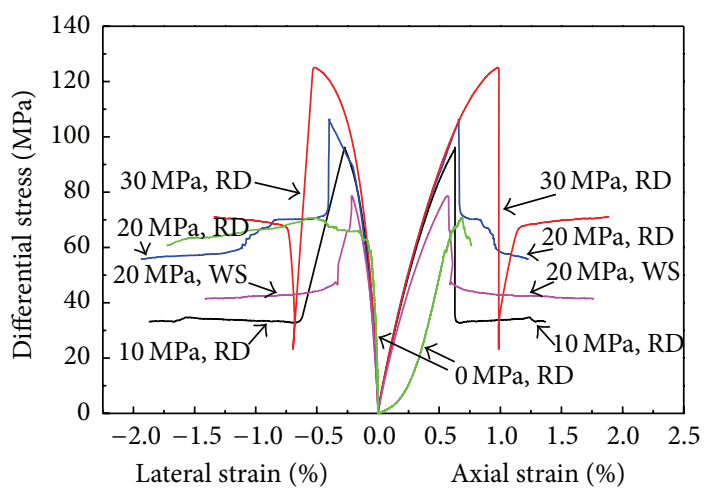

(e) $\beta=60^{\circ}$

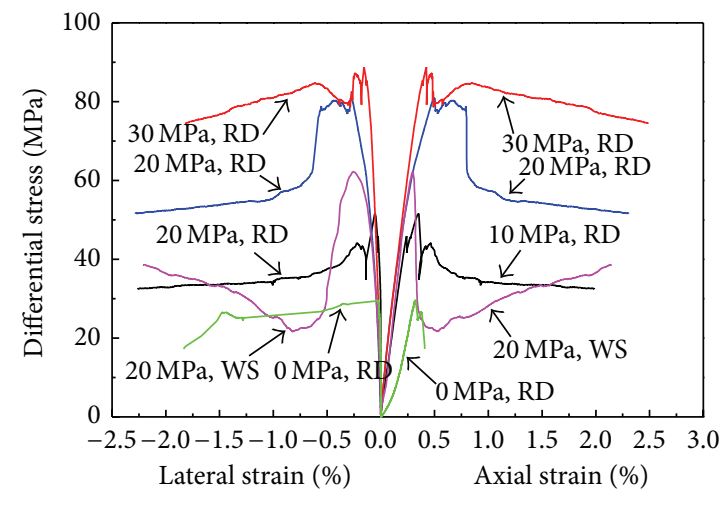

(b) $\beta=15^{\circ}$

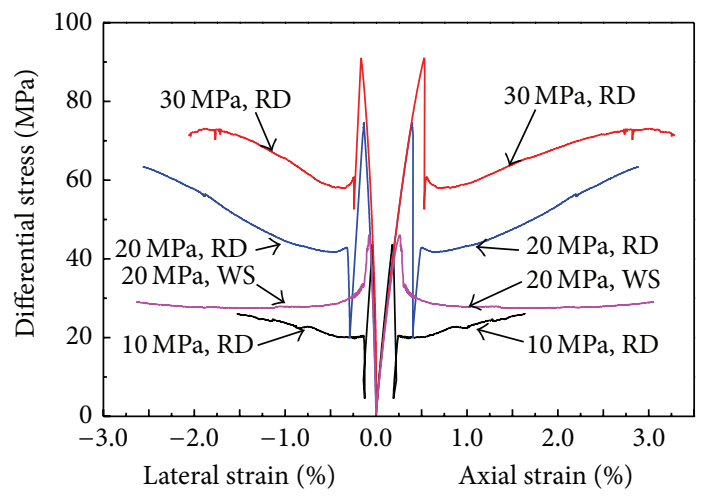

(d) $\beta=45^{\circ}$

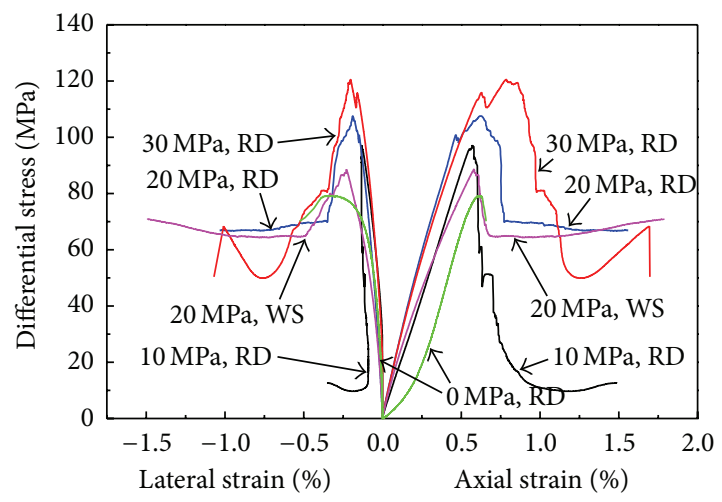

(f) $\beta=75^{\circ}$

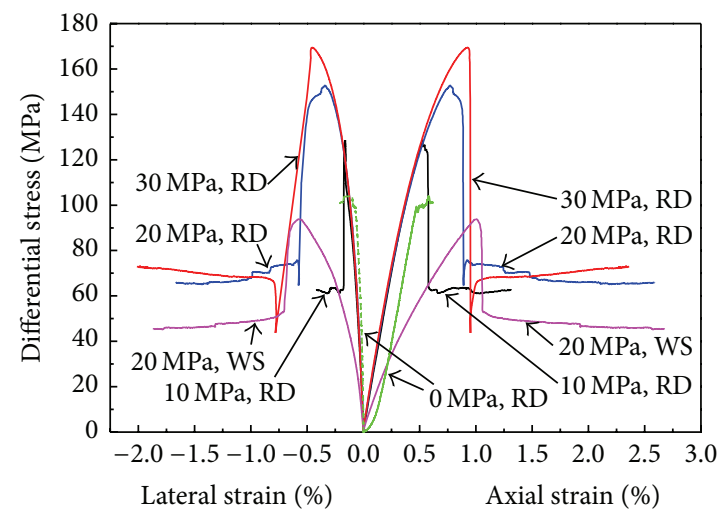

(g) $\beta=90^{\circ}$

FIGURE 4: The complete stress-strain curves of dry and saturated shale samples of various angles $(\beta)$, tested under different confining pressures. 


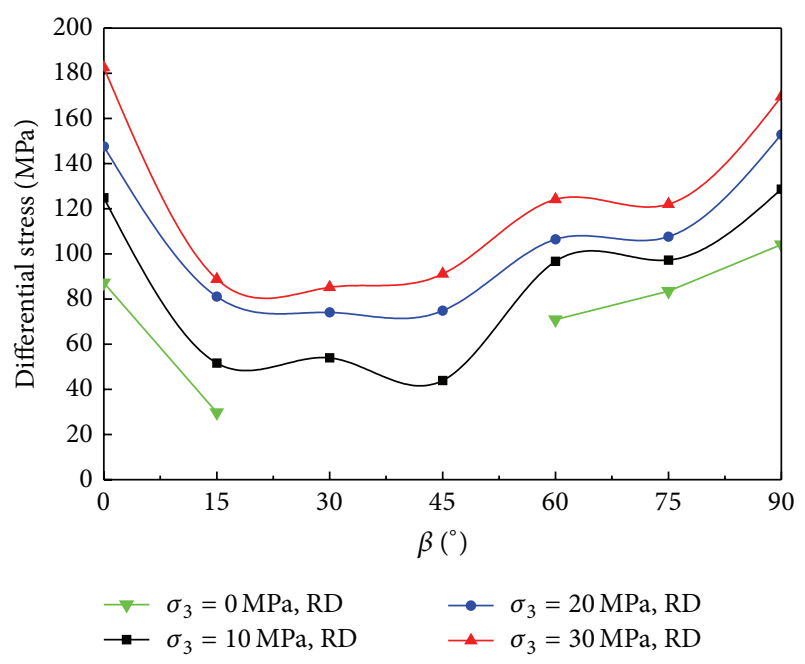

FIgURE 5: Differential stress at failure $\left(\sigma_{1}-\sigma_{3}\right)$ versus $\beta$ at different confining pressures $\left(\sigma_{3}\right)$.

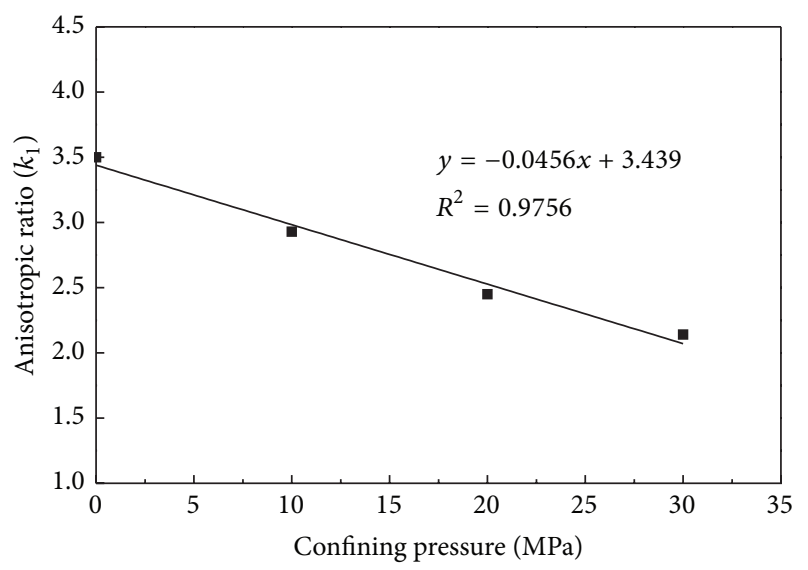

FIGURE 6: The relationship between anisotropic ratio $k_{1}$ and the confining pressure.

strength anisotropy decreases continuously as the confining pressure increases. Meanwhile, Figure 6 also shows that the relationship between $k_{1}$ and the confining pressure is linear and that the anisotropic effect of the failure strength will disappear at a sufficiently high confining pressure. When the confining pressure increases, rocks become more ductile, thereby inhibiting rock anisotropy. The same trend was also noted by other researchers $[5,8]$. For confining pressures $0,10,20$, and $30 \mathrm{MPa}, k_{2}$ is $0.84,0.97,0.96$, and 1.07 , respectively. Hence, the anisotropy of the samples parallel to the laminations is not markedly different to that of those perpendicular to the laminations. Figure 7 shows that the differential stress increases linearly with the confining pressure $\sigma_{3}$ for all correlation coefficients $\left(R^{2}\right)$ more than 0.9 .

5.1.2. The Mohr-Coulomb Failure Criterion. The Mohr-Coulomb failure criterion is widely used in ground control design

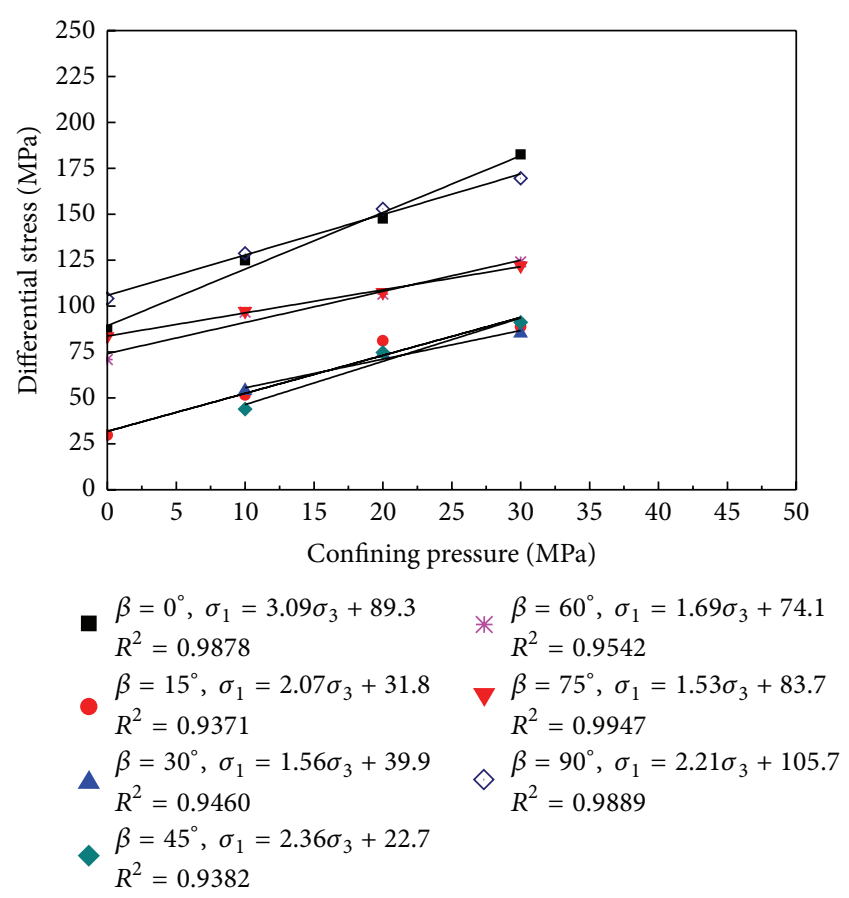

Figure 7: Differential stress at failure $\left(\sigma_{1}-\sigma_{3}\right)$ versus confining pressure $\left(\sigma_{3}\right)$ at various orientation angles $(\beta)$.

[23]. The cohesion (c) and internal friction angle $(\varphi)$ can be determined using (2) [35] as shown below:

$$
\begin{gathered}
\tan \psi=\frac{1+\sin \varphi}{1-\sin \varphi} \\
\sigma_{c}=\frac{2 c \cos \varphi}{1-\sin \varphi},
\end{gathered}
$$

where $\tan \psi=$ the slope of Mohr's envelope and $\sigma_{c}=$ the uniaxial compressive strength.

The slope and intercept of the lines in Figure 7 were used to determine the cohesion $(c)$ and internal friction angle $(\varphi)$ of room dried samples with different $\beta$. The results are plotted in Figure 8. Based on the constructed Mohr-Coulomb curves, the peak strength envelope of normal stress $(\sigma)$ and shear stress $(\tau)$ for different $\beta$ was obtained and shown below. It can be seen from Figure 8 that cohesion exhibits obvious anisotropic behavior and strongly depends on the loading orientation. Specifically, the cohesion of samples with $\beta$ between $15^{\circ}$ and $45^{\circ}$ is much smaller than others. This is because the failure mode of samples with $\beta$ between $15^{\circ}$ and $45^{\circ}$ is shearing along the laminations (Section 5.4). Obviously, the required force of shearing failure along the rock material is higher than that of shearing along the laminations.

Figure 8 indicates that the internal friction angle follows a "W-shaped" curve, which is neither consistent with the concave curve nor remaining constant as reported in $[4,8]$. The internal friction angle is anomalously high for $\beta=45^{\circ}$. After a closer examination of the fracture planes for $\beta=45^{\circ}$, the discrepancy could be attributed to differences in rock material variability even over a very short distance, even 


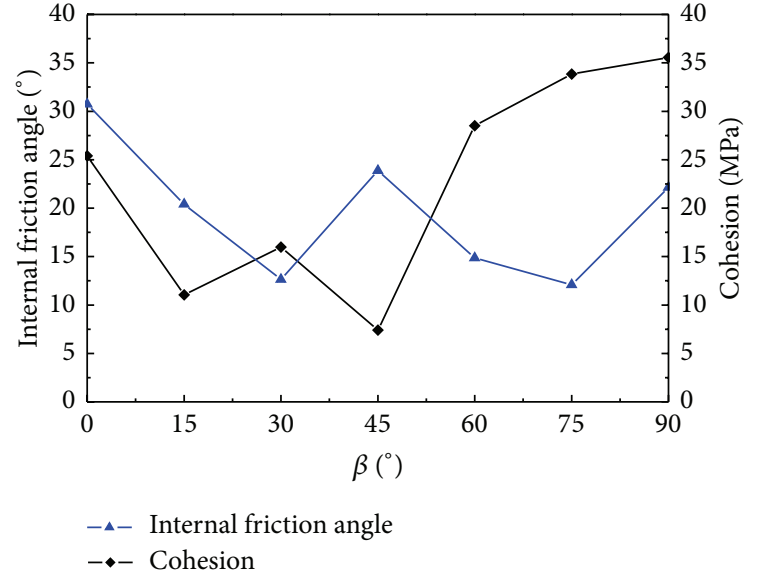

FIgURE 8: The friction angle and cohesion at various orientation angles were determined by plotting the linear Mohr-Coulomb failure envelopes.

though all specimens were drilled from the same block. Tiny sandstone streaks were found on the main fracture planes for $\beta=45^{\circ}$ and the granularity of sandstone is coarser than that of shale. Consider

$$
\begin{array}{cc}
\text { For } \beta=0^{\circ}, & \tau=\sigma \tan 30.73^{\circ}+25.4, \\
\text { For } \beta=15^{\circ}, & \tau=\sigma \tan 20.39^{\circ}+11.05, \\
\text { For } \beta=30^{\circ}, & \tau=\sigma \tan 12.64^{\circ}+15.97, \\
\text { For } \beta=45^{\circ}, & \tau=\sigma \tan 23.88^{\circ}+7.4, \\
\text { For } \beta=60^{\circ}, & \tau=\sigma \tan 14.86^{\circ}+28.5, \\
\text { For } \beta=75^{\circ}, & \tau=\sigma \tan 12.09^{\circ}+33.83, \\
\text { For } \beta=90^{\circ}, & \tau=\sigma \tan 22.14^{\circ}+35.55 .
\end{array}
$$

\subsection{Effect of Anisotropy and Confining Pressure on Deformability of Room Dried Samples}

5.2.1. Young's Modulus. In accordance with the recommended method by ASTM [34], the tangent Young modulus $\left(E_{t}\right)$ was calculated using the average slope of the axial stressaxial strain curve (Figure 4 ) at $50 \%$ of the peak strength. The relationship between the tangent Young modulus and the corresponding orientation $(\beta)$ at different confining pressures $\left(\sigma_{3}\right)$ for room dried specimens is presented in Figure 9. Note that the highest Young's modulus was always obtained at $\beta=$ $0^{\circ}$ no matter what confining pressure was applied, while lower values of Young's modulus occurred for samples with $\beta$ in the range of $45^{\circ}-75^{\circ}$. This is because the axial deformation for specimens in that angle range is mainly controlled by the laminations.

Similar to the relationship between the peak strength and the orientation angle of the laminations (i.e., $\beta$ ), a correlation has been obtained between Young's modulus and $\beta$, as shown in Figure 9. As the confining pressure increases, Young's modulus fluctuates only slightly overall.

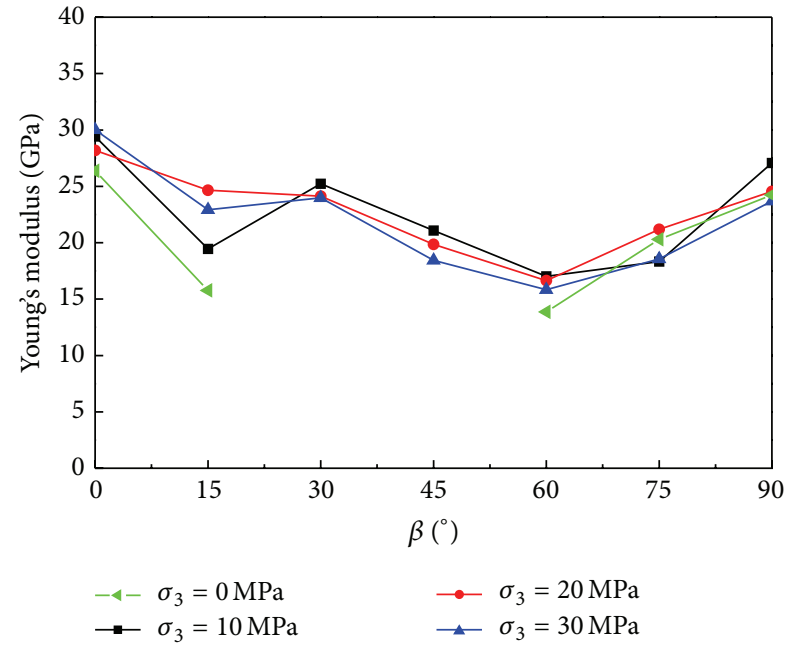

FIGURE 9: Tangent Young's modulus versus $\beta$ at different confining pressures $\left(\sigma_{3}\right)$.

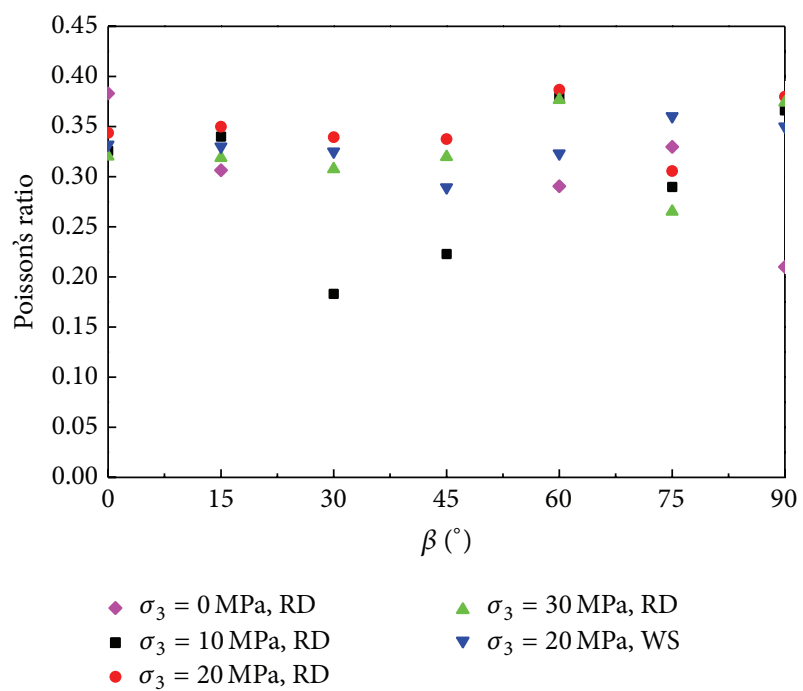

FIgURE 10: Poisson's ratio versus $\beta$ at different confining pressures $\left(\sigma_{3}\right)$.

5.2.2. Poisson's Ratio. Poisson's ratio was calculated from (4) based on the ASTM Standard [34], as shown in Figure 10. Most of the ratios range from 0.3 to 0.4 with small variations except when $\beta=30^{\circ}$ and $45^{\circ}$. It can be seen that Poisson's ratio does not exhibit apparent anisotropic behavior with respect to the orientation angle within the range of confining pressures tested. In fact, the ratio tends to vary only slightly. In addition, it also can be seen from Figure 10 that Poisson's ratio of the water saturated samples is generally smaller than that of room dried specimens except for those with $\beta=75^{\circ}$ :

$$
v=-\frac{\text { slope of axail curve }}{\text { slope of lateral curve }}=-\frac{E_{t}}{\text { slope of lateral curve }},
$$


where the slope of the lateral curve of the complete stressstrain curve (Figure 4) is determined in the same manner as was done for tangent Young's modulus, $E_{t}$.

5.2.3. Volumetric Strain. Figure 11 shows the variation of differential stress versus volumetric strain of room dried and saturated specimens under different confining pressures. When the axial load is initially applied, specimen tends to be compressed. As the differential stress approaches or just reaches the peak strength, the volume of the specimen starts to increase due to internal fracturing. This phenomenon is called specimen dilation. Shortly after the peak strength is reached, the net volumetric strain of the specimen becomes negative, which means the dilation continues in the postpeak stage. Note that, for the two specimens with $\beta=75^{\circ}$ and $\beta=90^{\circ}$ and both tested under confining pressure $=10 \mathrm{MPa}$, the result is invalid because the lateral deformation measurement device (LVDT 3) failed during tests. Meanwhile, since small cracks are gradually closed with the applied confining pressure, the amount of volume compression for specimens in triaxial compression is much smaller than that of the specimens in uniaxial compression.

\subsection{Effect of Water Content on Anisotropic Strength and} Deformation Behavior. Figure 12 shows compressive strength curves plotted against the orientation at confining pressure $20 \mathrm{MPa}$ for the room dried and saturated specimens. The cohesion and internal friction angle could not be determined directly for the water saturated specimens because tests were performed at a single confining pressure of $20 \mathrm{MPa}$.

In comparison to the room dried specimens, the intensity of anisotropy is obviously suppressed for water saturated specimens. The curve for the saturated specimens in Figure 12 is flat instead of shoulder-shaped. The compressive strength is maximum at $\beta=90^{\circ}$, followed by $75^{\circ}$, and the minimum is at $\beta=45^{\circ}$. Figure 12 also indicates that water has some impact on the compressive strength of shale. The average compressive strength of saturated specimens is $28.9 \%$ lower than that of the room dried specimens. The largest reduction of $54 \%$ occurs at $\beta=0^{\circ}$. Similar results were reported in $[25,27,28,30]$. In addition, it is quite interesting to note that strength reduction is sensitive to the orientation angle $(\beta)$; that is, water content has the greatest effect on compressive strength when the load is applied perpendicular and parallel to the laminations, while the minimum effect occurs when the orientation angle is around $30^{\circ}$.

Figure 13 compares Young's modulus of the room dried and saturated specimens under confining pressure of $20 \mathrm{MPa}$. The average and maximum reductions in Young's modulus of the water saturated samples are $26.1 \%$ and $62 \%$ (at $\beta=$ $90^{\circ}$ ), respectively. Similar to the effect of water content on compressive strength, the proportion of reduction of Young's modulus (i.e., shadow area in Figure 13) is related to the orientation angle $(\beta)$ of specimen laminations; that is, reduction in Young's modulus increases gradually from the middle $\left(\beta=45^{\circ}\right)$ to both ends $\left(\beta=0^{\circ}\right.$ and $\left.90^{\circ}\right)$. In other words, water has the largest effect on stiffness of shale specimen when the applied load is perpendicular and parallel to the laminations, but it has the minimum effect when the orientation angle is around $45^{\circ}$.

Li et al. [31] claimed that although various hypotheses including fracture energy reduction, capillary tension decrease, frictional reduction, chemical and corrosive deterioration, and effective stress decrease due to pore pressure have been put forward in an attempt to interpret the effect of water content, none of them provides a reliable and quantitative approach to the problem. Based on Li's theory, when rock contains sufficient water-sensitive constituents such as clay and silt, both cohesive strength and internal friction angle will be reduced due to the presence of water, which means that the shear strength of the potential failure plane decreases. Hence, the water saturated specimen will fail at a lower compressive strength than that of the dry specimen. van Eeckhout and Peng [6] stated that water enrichment in ground strata could have a profound effect on coal mine roofs. More specifically, when the water is absorbed into the roof shale, the shale will relax because of decreased elasticity. These might be the reason why compressive strength and Young's modulus decrease under the water saturated condition. Nevertheless, the mechanisms behind the phenomena that the higher water content of specimens reduces the anisotropic effect and the rationale behind it are still unclear.

\subsection{Failure Mechanism and Postfailure Behavior}

5.4.1. Failure Modes. As stated in the previous sections, the mechanical properties of shale (i.e., compressive strength, Young's modulus, and axial strain at peak strength) exhibit obvious anisotropic characteristics, which are believed to be related to the failure mechanisms in shale. It was observed that brittle fractures are deformation characteristics of all specimens at all three confining pressures. Generally speaking, the fracture planes develop in two modes of brittle fractures, that is, sliding along laminations and shearing of rock material. Since the maximum confining pressure applied in this research was $30 \mathrm{MPa}$, which is insufficiently high to translate the failure mode from brittle to plastic flow or kink flow as reported in $[4,8]$. Figure 14 shows all the samples after testing, whereas Figure 15 illustrates two typical modes of specimen failure.

(1) Types of Fracture. There are two types of fracture (Figure 16). In the first type (Figure 16(a)), the laminations intersect one or both of the end surfaces of the specimen. In this case, when a fracture along the laminations occurs, it intersects one or both interfaces between the specimen end and the platen. As the test continues, the postfailure stressstrain curve fluctuates without losing strength (Figures 4(a), 4(b), and 4(f)). It finally drops down gradually as the test continues further. In the second type (Figure 16(b)), fractures occur in the shale matrix or along the laminations. In this case, both ends of the fracture are located on the free surface of the specimen without the constraint of the interface between the specimen ends and the platen. Consequently, its postfailure curve is a very rapid and sudden drop of strength (Figures 4(d) and 4(e)) is observed. 


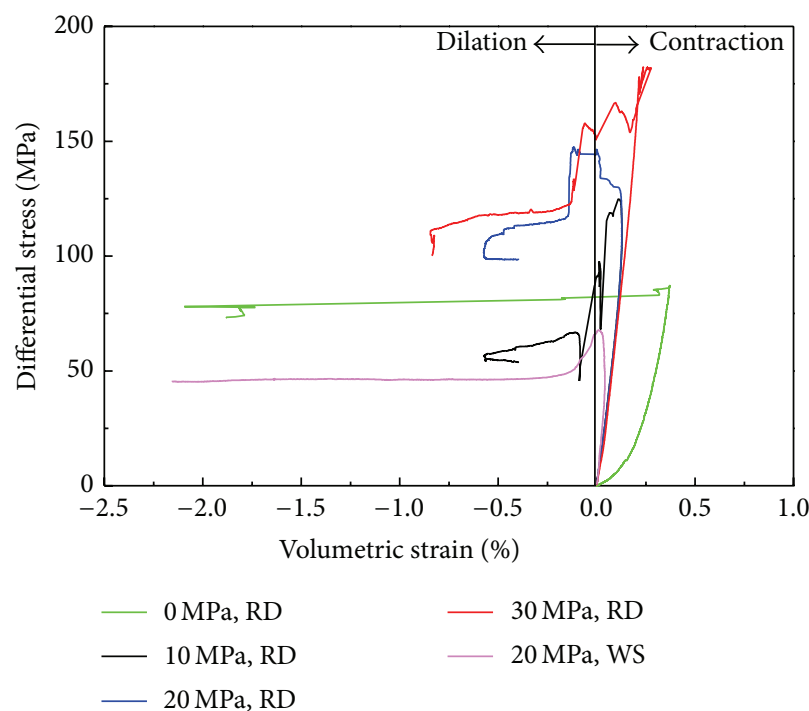

(a) $\beta=0^{\circ}$

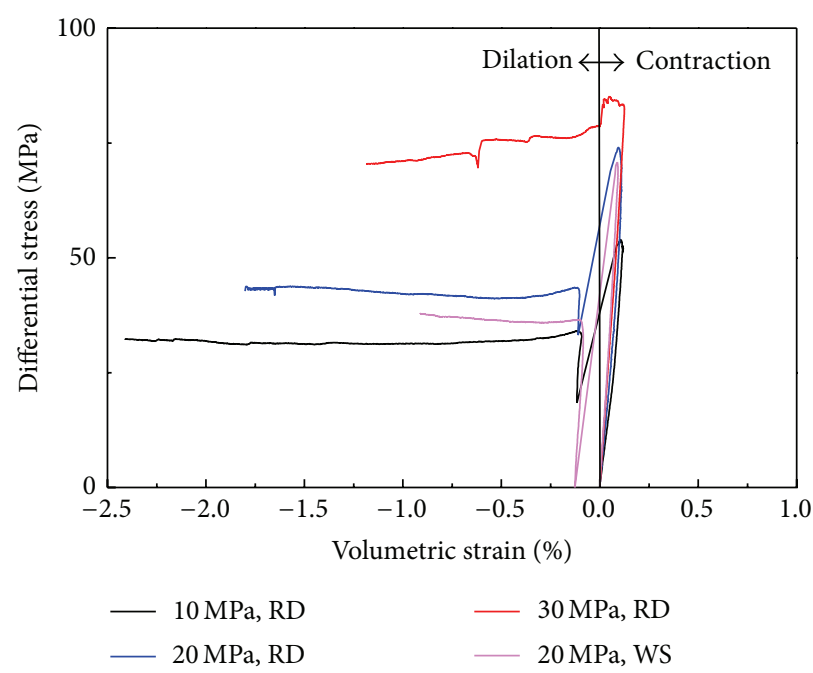

(c) $\beta=30^{\circ}$

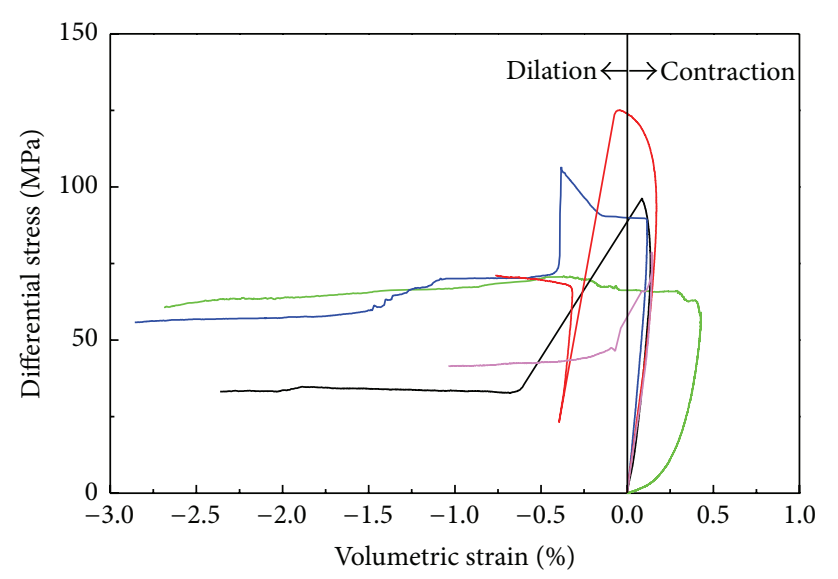

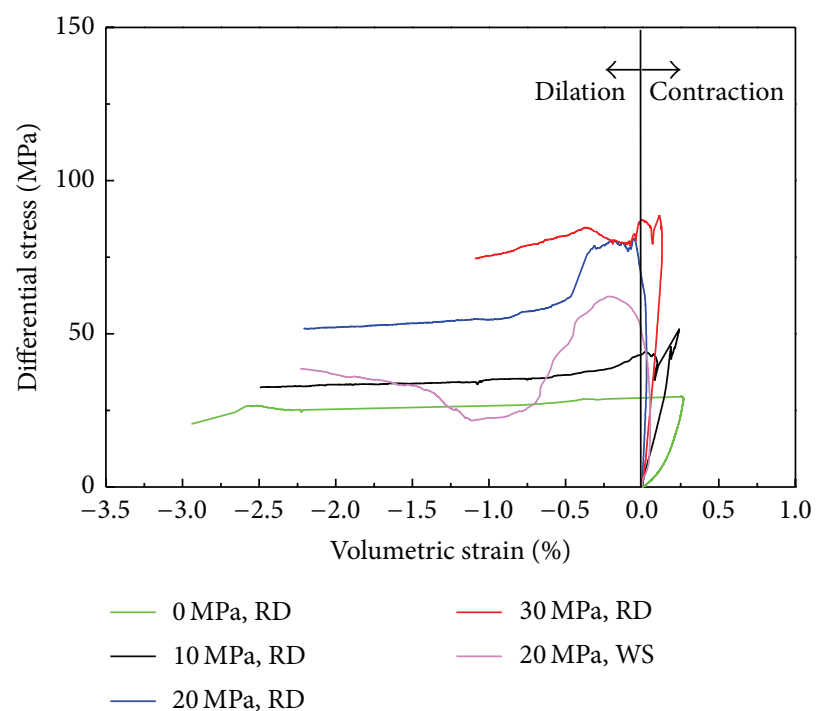

(b) $\beta=15^{\circ}$

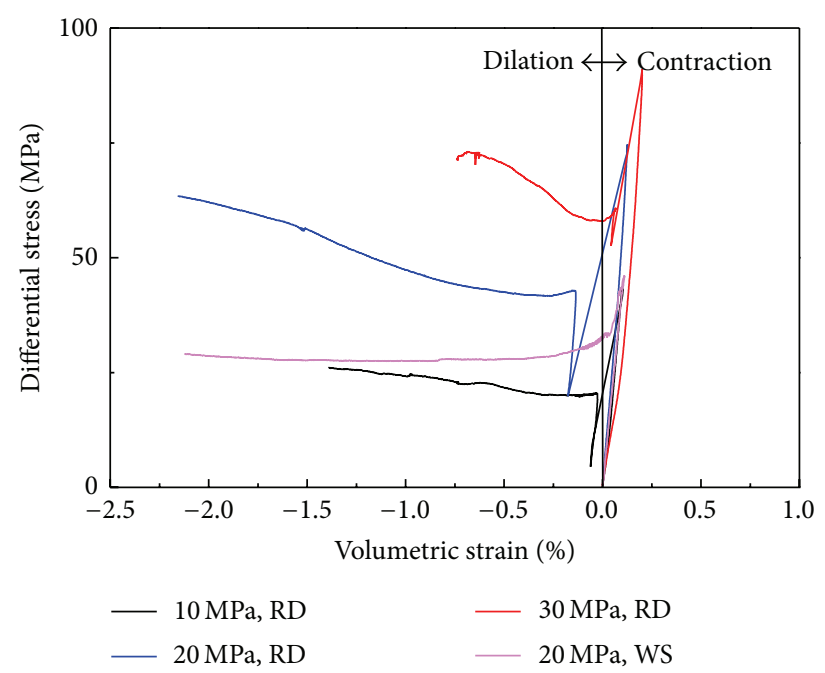

(d) $\beta=45^{\circ}$

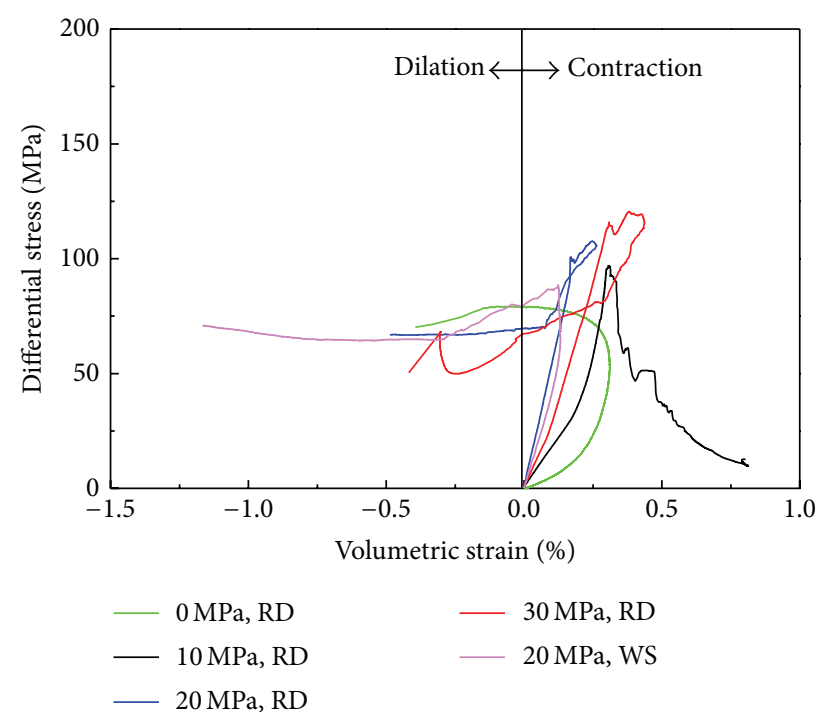

(f) $\beta=75^{\circ}$

(e) $\beta=60^{\circ}$

Figure 11: Continued. 


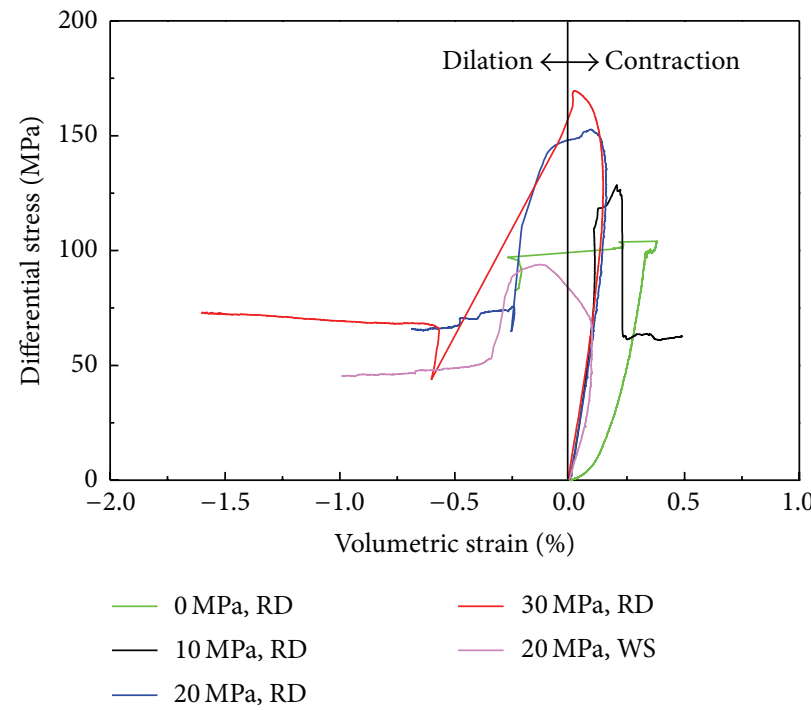

(g) $\beta=90^{\circ}$

FiguRE 11: The differential stress-volumetric strain curves of dry and saturated shale samples of various angles, $\beta$, tested under different confining pressures.

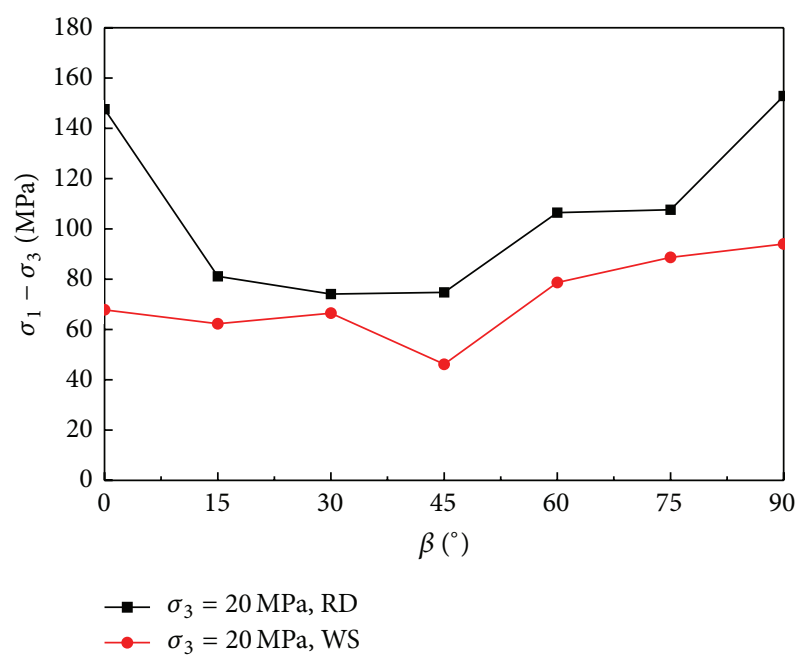

FIGURE 12: Comparison of the compressive strength of the room dried and water saturated specimens.

(2) Fracture Developed along the Laminations. For samples with $\beta$ between 15 and $45^{\circ}$ (Figures 4,14 , and 15(a)), specimens always failed suddenly along the lamination, because at failure the shear stress acting on the laminations exceeds their shear strength. Hence, the strength of samples with $\beta$ between 15 and $45^{\circ}$ was dictated by the shear strength of the laminations.

(3) Fracture Developed across Rock Material. For samples with $\beta=0^{\circ}$ and between 60 and $90^{\circ}$ (Figures 4,14 , and 15(b)), fractures developed in the rock material, which can be attributed to the fact that the shear stress acting on the laminations was smaller than the shear strength along

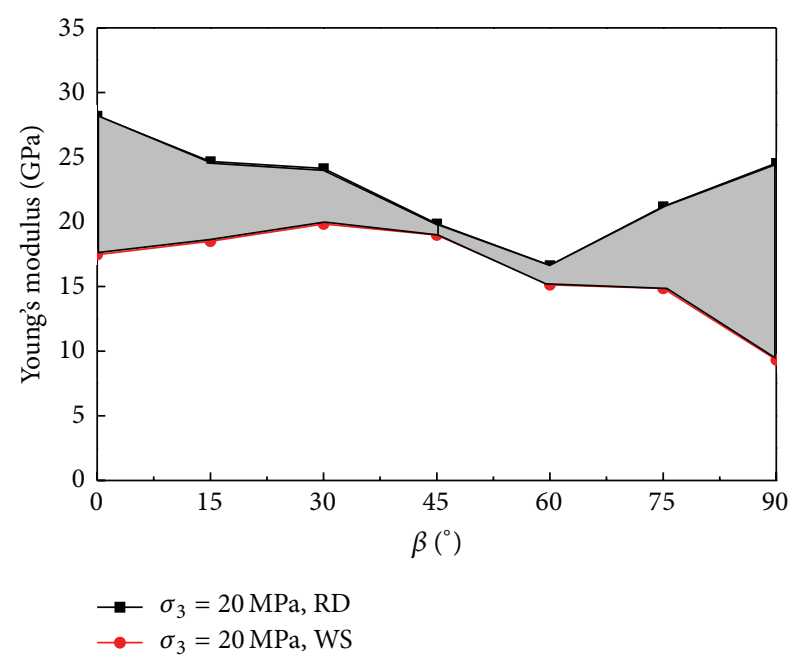

FIGURE 13: Comparison of the tangent Young modulus of the room dried and saturated specimens.

the laminations. Consequently, failure was dictated by the shale matrix instead of the laminations.

\section{Conclusion}

Coal measure shale is one of the most widely distributed rock materials in underground coal mines, and most ground control failures are related to coal measure shale. Although lots of research work have been done on the anisotropic behavior of different types of rocks or artificial materials, more detailed laboratory work on anisotropic strength and deformation behavior of coal measure shale, especially taking into consideration the effect of water content, is still needed 


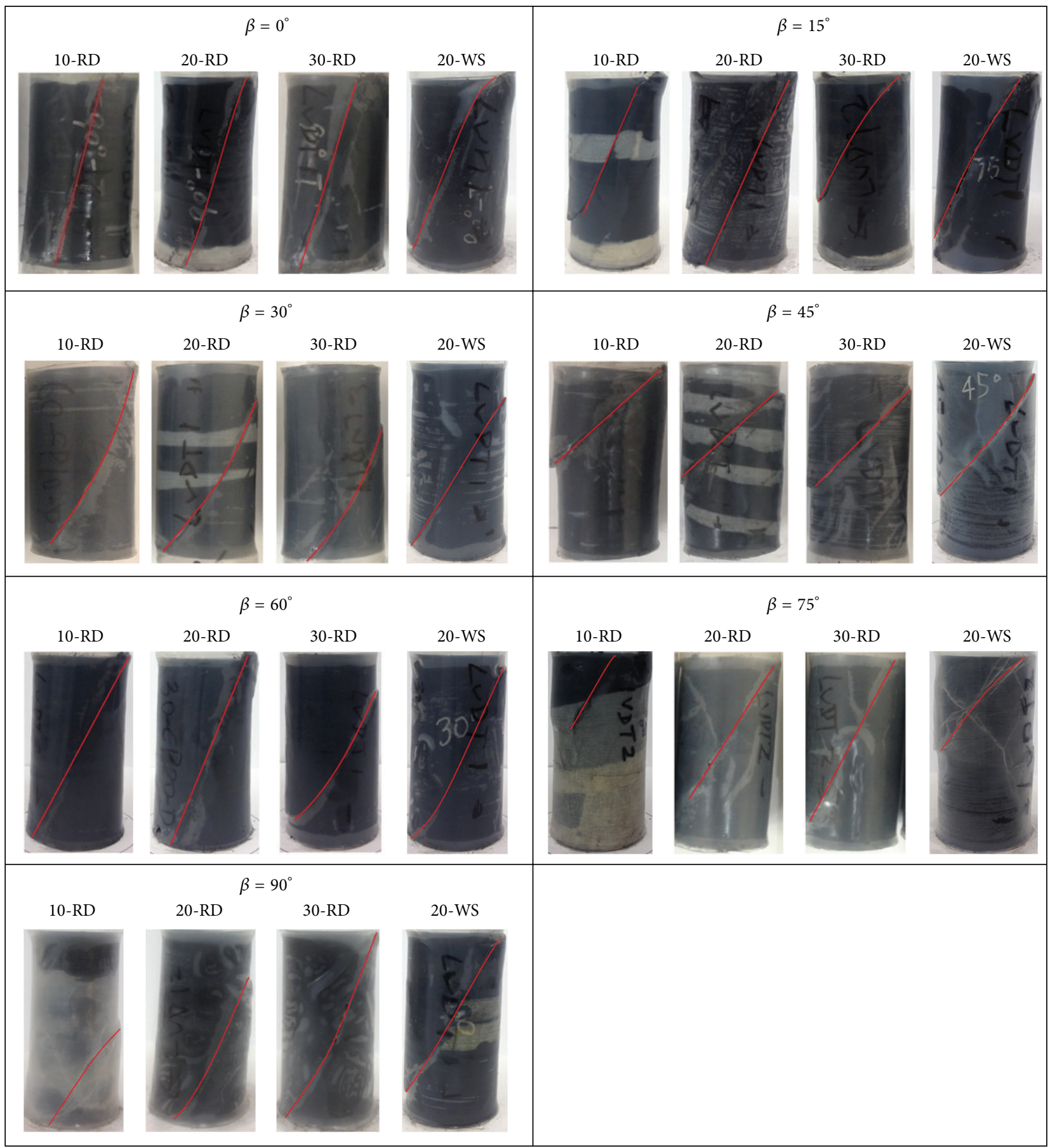

\section{— Main fracture}

$\mathrm{RD}$ : room dried specimen

WS: water saturated specimen

FIgURE 14: Photos of room dried samples at different $\beta$ under various confining pressures after testing.

in order to understand better the mechanisms of many ground control failures. In this study, the uniaxial and triaxial compression tests have been conducted on samples of coal measure shale, under both room dried and water saturated conditions, to study the effect of anisotropy and water content on the strength, deformability, and failure modes of coal measure shale.

Results of tests show that the strength and deformation behavior of room dried samples are strongly affected by the direction of the laminations with respect to that of the major 
Fracture developed along the lamination

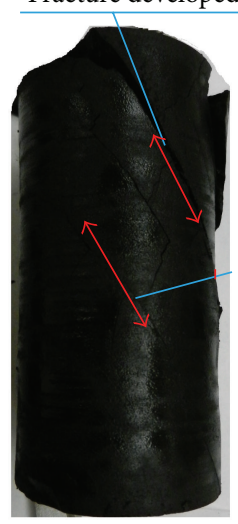

$\beta=30^{\circ}, \sigma_{3}=30 \mathrm{MPa}$

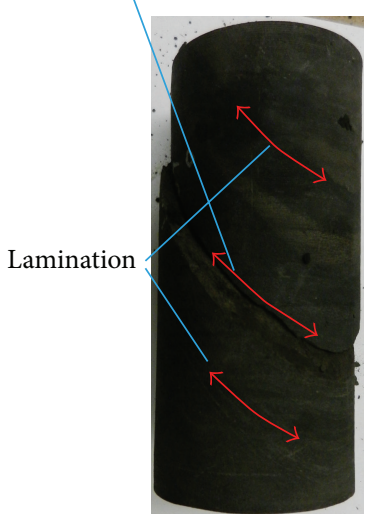

$\beta=45^{\circ}, \sigma_{3}=30 \mathrm{MPa}$

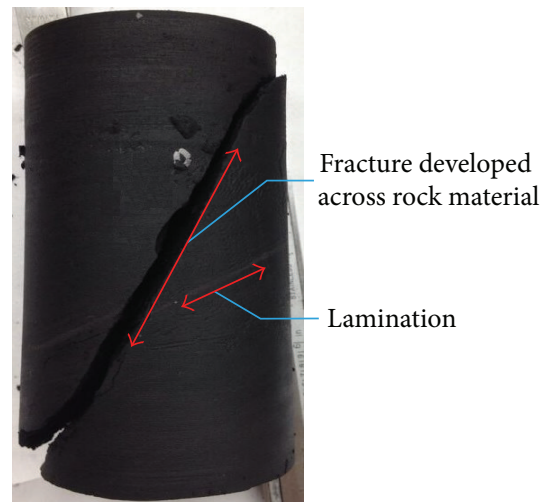

$\beta=60^{\circ}, \sigma_{3}=30 \mathrm{MPa}$

(b) Fracture developed across shale material

(a) Fracture developed along the lamination

FIGURE 15: Photos showing two typical failure modes.
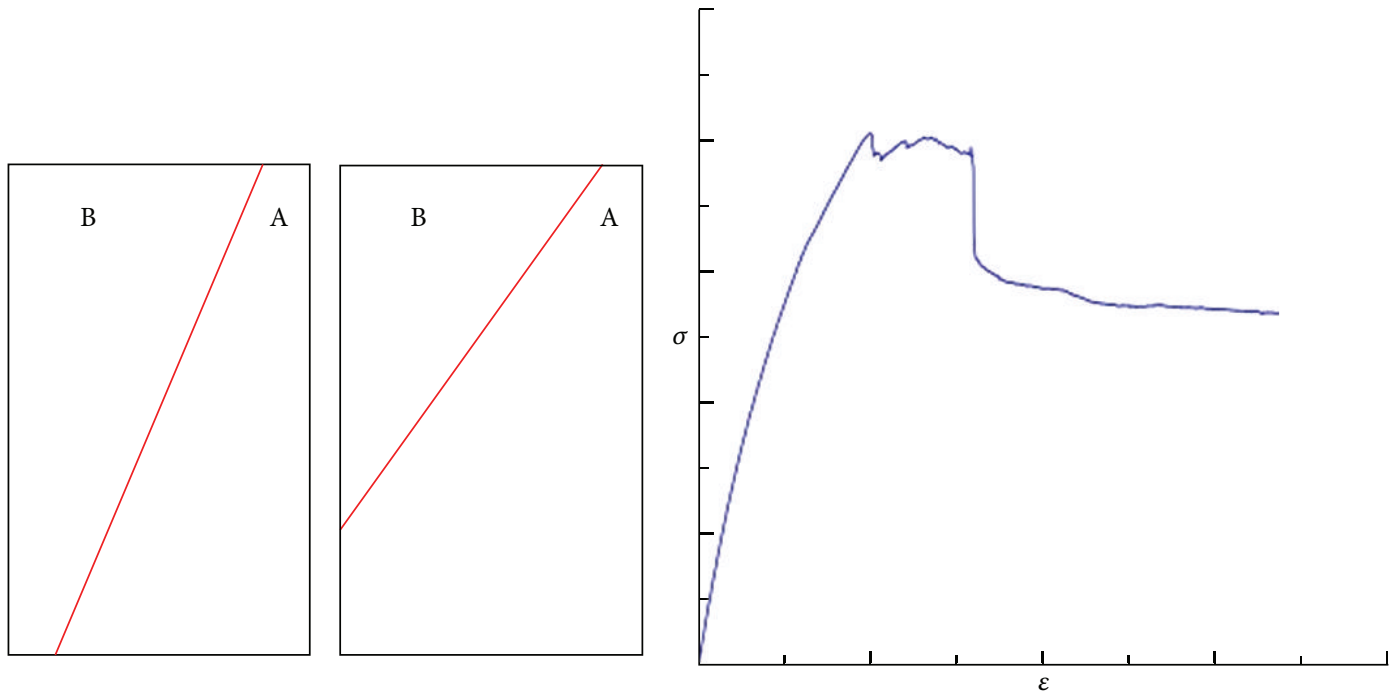

(a) Fracture type 1

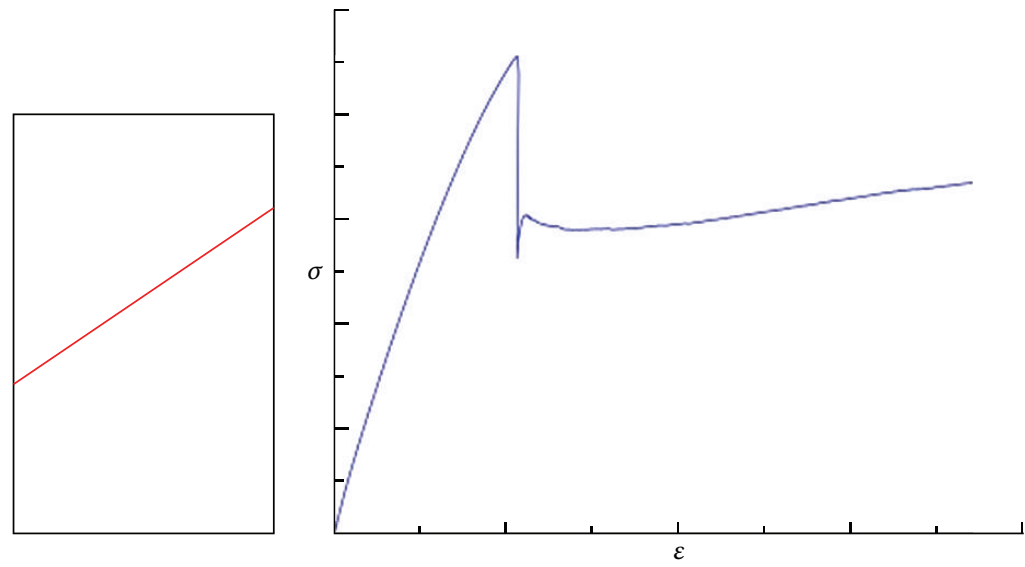

(b) Fracture type 2

Figure 16: Type of fractures. 
principal stress. The maximum strength always occurs at $\beta=0^{\circ}$ or $\beta=90^{\circ}$. Meanwhile, the minimum strength always occurs for samples with $\beta$ between $30^{\circ}$ and $45^{\circ}$. As the confining pressure increases, the compressive strength increases uniformly whereas the anisotropic effect of strength decreases. Based on the Mohr-Coulomb failure criterion, the cohesion ranges from 7.4 to $35.5 \mathrm{MPa}$ with the higher values being found among samples with $\beta=60^{\circ}-90^{\circ}$. The tangent Young modulus also exhibits anisotropic behavior with respect to $\beta$ with the maximum being for $\beta=0^{\circ}$. Furthermore, as the confining pressure increases, Young's modulus only fluctuates slightly.

On the other hand, the impact of water content on compressive strength and deformation behavior is very evident. In comparison to room dried samples, the average compressive strength and Young's modulus reductions of water saturated samples are $28.9 \%$ and $26.1 \%$, respectively, whereas the maximum reductions are $54 \%$ and $62 \%$, respectively. Meanwhile, test results also indicate that these reductions are strongly related to the orientation angle $(\beta)$. Water content has more effect on strength and Young's modulus when the applied load is perpendicular and parallel to the lamination orientation and has minimum effect when the orientation angle falls in the range of $30^{\circ}-45^{\circ}$. Furthermore, compared to room dried samples, the anisotropy of compressive strength and Young's modulus of water saturated samples is clearly reduced.

There are two types of failure mechanisms for shale: sliding along laminations and shearing of rock matrix. The two types of postfailure stress-strain curve are strongly dependent on the failure mechanism. One is a sudden and rapid drop down, while the other fluctuates before slopping down gently to the residual strength.

\section{Conflict of Interests}

The authors declare that there is no conflict of interests regarding the publication of this paper.

\section{Acknowledgments}

This study was sponsored by National High Technology Research and Development Program of China (no. 2012AA062100), National Natural Science Foundation of China (no. 51074164), the Program for New Century Excellent Talents in University of China (no. NCET-10-0770), and China Scholarship Council. The authors would like to express their sincere appreciation to Mr. Joe Andrews (Ark Land Company, WV, USA) and Mr. Kevin Andrews (Cardno MM\&A, VA, USA) for their help in obtaining the samples and to Dr. Brijes Mishra, Mr. Xu Tang, and Mr. Priyesh Verma of West Virginia University for their contribution in this study.

\section{References}

[1] S. S. Peng, Ground Control Failures: A Pictorial View of Case Studies, Syd S. Peng, Morgantown, WVa, USA, 2007.

[2] S. S. Peng, "Topical areas of research needs in ground controla state of the art review on coal mine ground control," Journal of
China University of Mining \& Technology, vol. 44, no. 1, pp. 1-8, 2015.

[3] W. Li, J. Bai, S. S. Peng, X. Wang, and Y. Xu, "Numerical modeling for yield pillar design: a case study," Rock Mechanics and Rock Engineering, vol. 48, no. 1, pp. 305-318, 2013.

[4] F. A. Donath, "Effects of cohesion and granularity on deformational behavior of anisotropic rock," Geological Society of America, vol. 135, pp. 95-128, 1972.

[5] H. Niandou, J. F. Shao, J. P. Henry, and D. Fourmaintraux, "Laboratory investigation of the mechanical behaviour of tournemire shale," International Journal of Rock Mechanics and Mining Sciences, vol. 34, no. 1, pp. 3-16, 1997.

[6] E. M. van Eeckhout and S. S. Peng, "The effect of humidity on the compliances of coal mine shales," International Journal of Rock Mechanics and Mining Sciences and, vol. 12, no. 11, pp. 335340, 1975.

[7] M. E. Chenevert and C. Gatline, "Mechanical anisotropies of laminated sedimentary rocks," The Society of Petroleum Engineers, vol. 5, no. 1, pp. 67-77, 1965.

[8] R. McLamore and K. E. Gray, "The mechanical behavior of anisotropic sedimentary rocks," Journal of Manufacturing Science and Engineering, vol. 89, no. 1, pp. 62-73, 1967.

[9] A. Fahimifar, "Strength and deformation properties of a schist rock in Isfahan," Iranian Journal of Science and Technology, Transaction B: Engineering, vol. 28, no. 5, pp. 617-622, 2004.

[10] M. H. B. Nasseri, K. S. Rao, and T. Ramamurthy, "Anisotropic strength and deformation behavior of Himalayan schists," International Journal of Rock Mechanics and Mining Sciences, vol. 40, no. 1, pp. 3-23, 2003.

[11] V. K. Singh, D. Singh, and T. N. Singh, "Prediction of strength properties of some schistose rocks from petrographic properties using artificial neural networks," International Journal of Rock Mechanics and Mining Sciences, vol. 38, no. 2, pp. 269-284, 2001.

[12] T. Ramamurthy, "Strength and modulus responses of anisotropic rocks," Comprehensive Rock Engineering, vol. 1, pp. 313329, 1993.

[13] G. Khanlari, B. Rafiei, and Y. Abdilor, "Evaluation of strength anisotropy and failure modes of laminated sandstones," Arabian Journal of Geosciences, pp. 1-14, 2014.

[14] Y. M. Tien, M. C. Kuo, and C. H. Juang, "An experimental investigation of the failure mechanism of simulated transversely isotropic rocks," International Journal of Rock Mechanics and Mining Sciences, vol. 43, no. 8, pp. 1163-1181, 2006.

[15] Y. M. Tien and P. F. Tsao, "Preparation and mechanical properties of artificial transversely isotropic rock," International Journal of Rock Mechanics and Mining Sciences, vol. 37, no. 6, pp. 1001-1012, 2000.

[16] Y. M. Tien and M. C. Kuo, "A failure criterion for transversely isotropic rocks," International Journal of Rock Mechanics and Mining Sciences, vol. 38, no. 3, pp. 399-412, 2001.

[17] J. C. Jaeger, "Shear failure of anisotropic rocks," Geological Magazine, vol. 97, no. 1, pp. 65-72, 1960.

[18] R. Nova, "The failure of transversely isotropic rocks in triaxial compression," International Journal of Rock Mechanics and Mining Sciences and, vol. 17, no. 6, pp. 325-332, 1980.

[19] O. Cazacu, N. D. Cristescu, J. F. Shao, and J. P. Henry, "A new failure criterion for transversely isotropic rocks," International Journal of Rock Mechanics and Mining Sciences, vol. 3, no. 1, pp. 89-103, 1998.

[20] H. Ding, X. Miao, F. Ju, X. Wang, and Q. Wang, "Strata behavior investigation for high-intensity mining in the water-rich coal 
seam," International Journal of Mining Science and Technology, vol. 24, no. 3, pp. 299-304, 2014.

[21] C. Meng, X. Li, Q. Yao, and J. Zhou, "Numerical research on stability control of roofs of water-rich roadway," International Journal of Mining Science and Technology, vol. 24, no. 3, pp. 409416, 2014.

[22] Y. Zhang, S. Tu, Q. Bai, and J. Li, "Overburden fracture evolution laws and water-controlling technologies in mining very thick coal seam under water-rich roof," International Journal of Mining Science and Technology, vol. 23, no. 5, pp. 693-700, 2013.

[23] S. S. Peng, Coal Mine Ground Control, Syd S. Peng, Morgantown, WVa, USA, 3rd edition, 2008.

[24] G. M. Molinda, D. C. Oyler, and H. Gurgenli, "Identifying moisture sensitive roof rocks in coal mines," in Proceedings of the 25th International Conference on Ground Control in Mining, pp. 57-64, West Virginia University, Morgantown, WVa, USA, 2006.

[25] E. M. van Eeckhout, The effect of moisture on the mechanical properties of coal mine shales [Ph.D. thesis], University of Minnesota, Minneapolis, Minn, USA, 1974.

[26] M. E. Chenevert, "Shale alteration by water adsorption," Journal of Petroleum Technology, vol. 22, no. 9, pp. 1141-1148, 1970.

[27] B. Vasarhelyi, "Some observations regarding the strength and deformability of sandstones in dry and saturated conditions," Bulletin of Engineering Geology and the Environment, vol. 62, no. 3, pp. 245-249, 2003.

[28] B. Vásárhelyi, "Statistical analysis of the influence of water content on the strength of the miocene limestone," Rock Mechanics and Rock Engineering, vol. 38, no. 1, pp. 69-76, 2005.

[29] B. Vásárhelyi and P. Ván, "Influence of water content on the strength of rock," Engineering Geology, vol. 84, no. 1-2, pp. 7074, 2006.

[30] A. B. Hawkins and B. J. McConnell, "Sensitivity of sandstone strength and deformability to changes in moisture content," Quarterly Journal of Engineering Geology, vol. 25, no. 2, pp. 115130, 1992.

[31] D. Li, L. N. Y. Wong, G. Liu, and X. Zhang, "Influence of water content and anisotropy on the strength and deformability of low porosity meta-sedimentary rocks under triaxial compression," Engineering Geology, vol. 126, pp. 46-66, 2012.

[32] Z. A. Erguler and R. Ulusay, "Water-induced variations in mechanical properties of clay-bearing rocks," International Journal of Rock Mechanics and Mining Sciences, vol. 46, no. 2, pp. 355-370, 2009.

[33] M. Talesnick and S. Shehadeh, "The effect of water content on the mechanical response of a high-porosity chalk," International Journal of Rock Mechanics and Mining Sciences, vol. 44, no. 4, pp. 584-600, 2007.

[34] ASTM D7012-10, Standard Test Method for Compressive Strength and Elastic Moduli of Intact Rock Core Specimens Under Varying States of Stress and Temperatures, ASTM International, West Conshohocken, Pa, USA, 2010.

[35] B. H. G. Brady and E. T. Brown, Rock Mechanics for Underground Mining, Springer, Berlin, Germany, 3rd edition, 2006. 

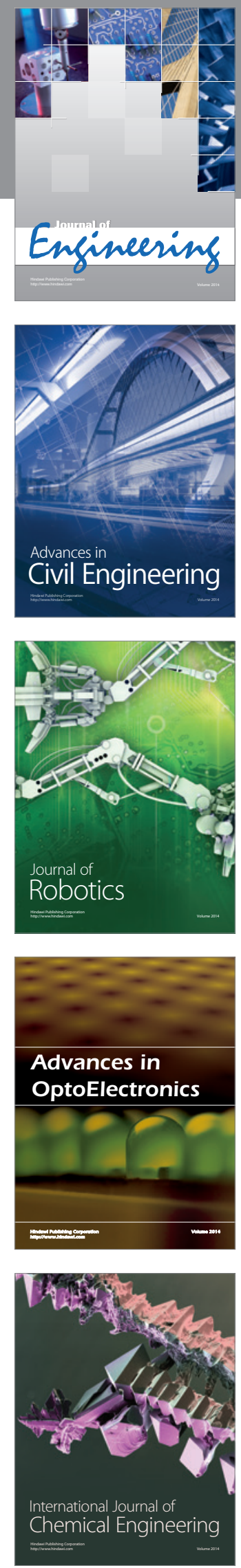

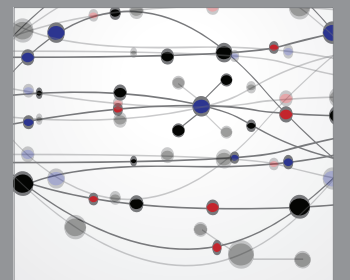

The Scientific World Journal
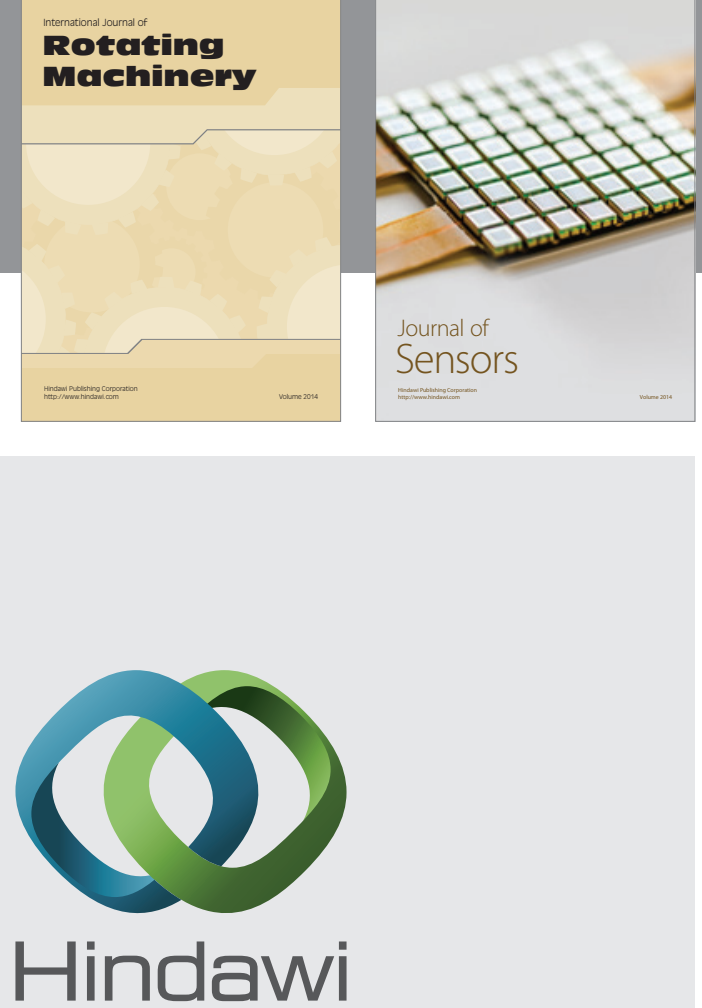

Submit your manuscripts at http://www.hindawi.com
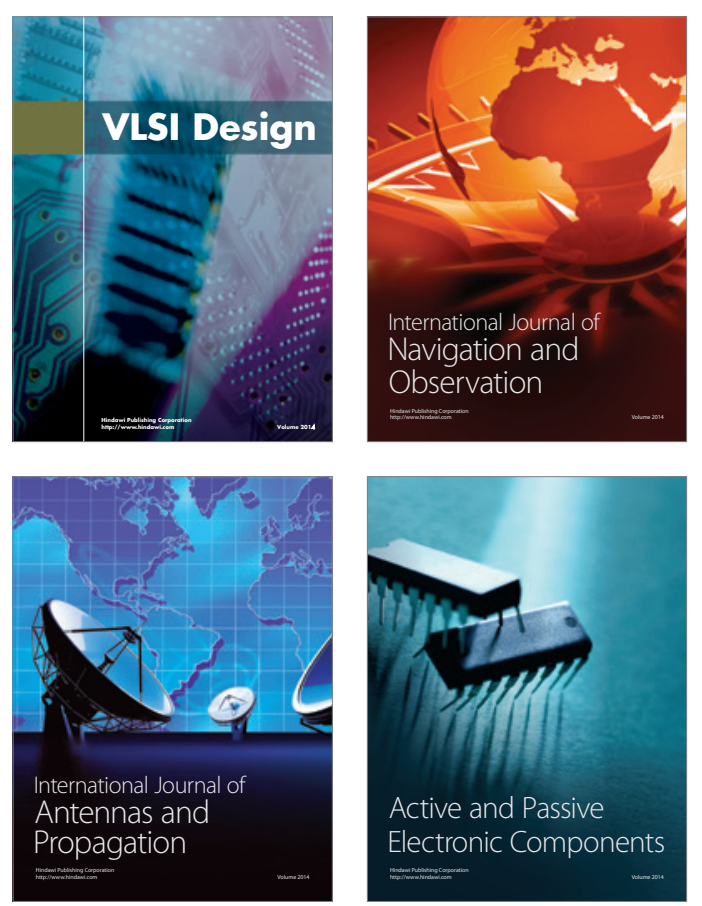
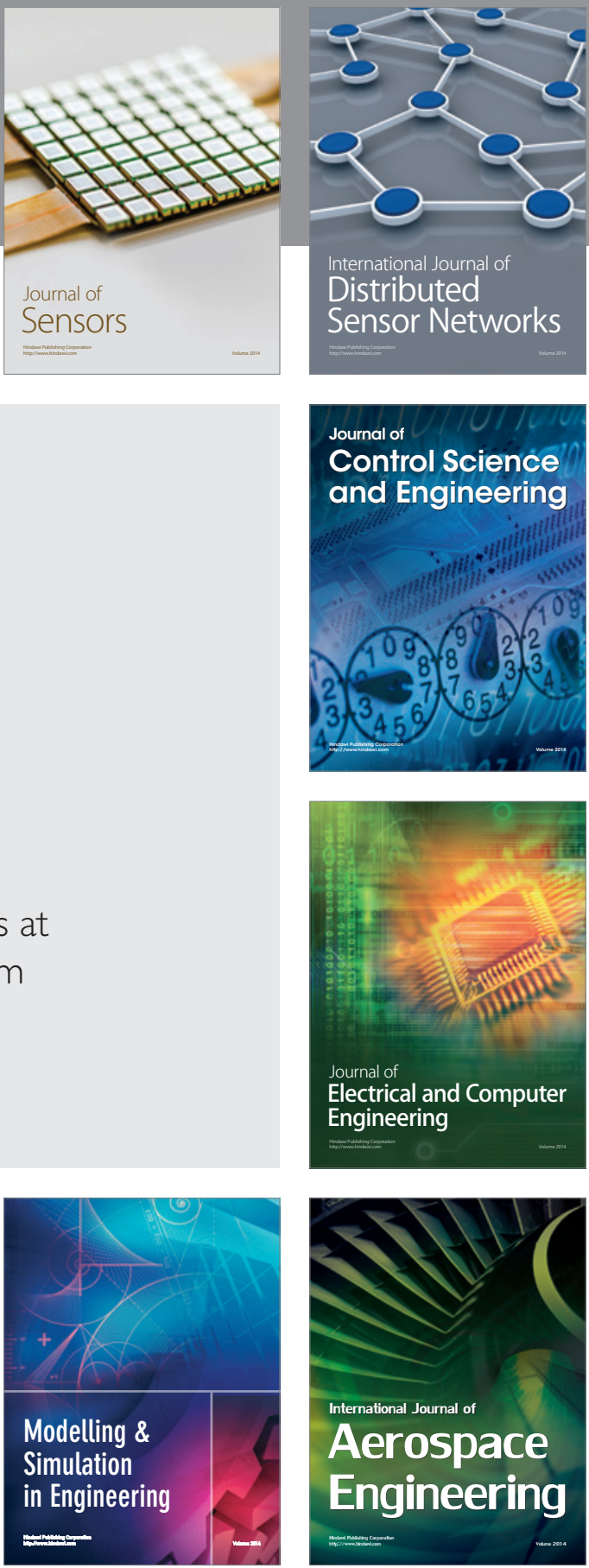

Journal of

Control Science

and Engineering
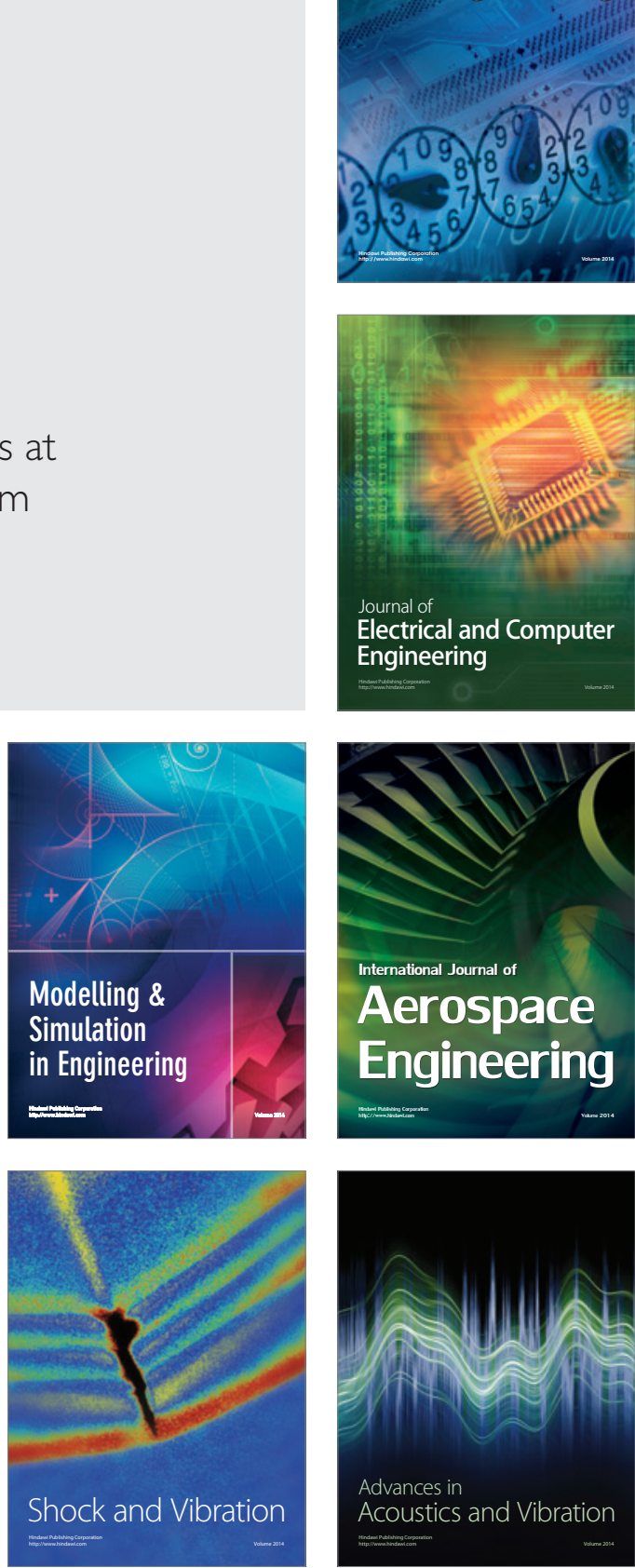